\title{
Occupational Exposure to Pesticides: Blood Cholinesterase Activity in a Farming Community in Ghana
}

\author{
William J. Ntow $\cdot$ Laud M. Tagoe $\cdot$ Pay Drechsel $\cdot$ \\ Peter Kelderman · Elvis Nyarko $\cdot$ Huub J. Gijzen
}

Received: 14 September 2007/ Accepted: 22 October 2007/Published online: 27 December 2008

(C) The Author(s) 2007. This article is published with open access at Springerlink.com

\begin{abstract}
A survey was undertaken to establish the extent of pesticide exposure in a farming community. Cholinesterase (ChE) activity in whole blood was used as a marker for assessing exposure to pesticides. Complete data were gathered for 63 farmers at Akumadan (exposed) and 58 control subjects at Tono, both prominent vegetable-farming communities in Ghana, by means of a questionnaire and blood cholinesterase analyses (acetylcholine assay). Although whole-blood ChE was significantly lower in the exposed than the control participants, it was not significantly correlated with either confounders of age, sex, body weight, and height or high-risks practices. The high-risks practices revealed during the survey included lack of use of
\end{abstract}

W. J. Ntow $(\bowtie)$

CSIR Water Research Institute, P.O. Box AH 38, Achimota, Ghana

e-mail: w_ntow@yahoo.co.uk

\section{M. Tagoe}

Environmental Science Department, University of Ghana, Legon, Ghana

P. Drechsel

West Africa Office, International Water Management Institute, Accra, Ghana

P. Kelderman · H. J. Gijzen

UNESCO-IHE Institute for Water Education, Westvest 7, 2611, AX, Delft, The Netherlands

E. Nyarko

Department of Oceanography, University of Ghana, Legon, Ghana

H. J. Gijzen

UNESCO Jakarta Office, Regional Bureau for Science for Asia and Pacific, JI. Galuh II, Kebayoran Baru, Jakarta 12110, Indonesia personal protective clothing, short reentry intervals, and wrong direction of spraying of pesticides by hand or knapsack sprayer. About $97 \%$ of exposed participants had experienced symptoms attributable to pesticide exposure. The frequent symptoms were reported as weakness and headache. There is the need to review safety precautions in the use and application of pesticides in Ghana.

The use of pesticides to control insect pests, which cause damage to crops and result in severe loss in food production in tropical countries like Ghana, has become recognized and accepted as an essential component of modern agricultural production. However, prolonged use of pesticides along with lack of suitable averting behavior/use of basic protective requisites enhances the probability of accidental intoxication significantly. In Ghana, pesticides are typically applied to vegetables. Safety measures are generally poorly applied and workers lack proper knowledge or training in safe handling and application of these chemicals (Ntow et al. 2006). These practices might produce a population with high exposures.

Two kinds of measurement (enzyme activities in blood and unchanged pesticides and their metabolites in urine or blood) have been used in biological monitoring for assessing exposure to pesticides. The assays of cholinesterase (ChE) activity in whole blood and erythrocytes are mainly applied to estimate inhibition by organophosphates (OPs) and carbamates (He 1993; WHO Task Group 1986a, 1986b). However, under many field conditions, procedures using whole blood are more practical than those using separated erythrocytes (He 1993). Additionally, because the serum and erythrocyte enzymes of whole human blood differ importantly, studies on either enzyme alone are inadequate to value the role played by the ChE activity of 
whole blood (Alles and Hawes 1939, downloaded from www.jbc.org on December 19, 2006).

Many organophosphate (OP) and carbamate pesticides are detrimental to nontarget organisms such as aquatic organisms, birds, reptiles, and mammals (including humans). OPs and carbamates act as anticholinesterase (anti-ChE) agents. Because of the specificity of this relationship, depression of $\mathrm{ChE}$ activity has been used as a biomarker of exposure to these classes of pesticides with few reports on humans (Farahat et al. 2003; Fenske et al. 2005; Ohayo-Mitoko et al. 2000; Nielsen and Andersen 2002). There is relatively little research on Ghanaian workers occupationally exposed to $\mathrm{OP}$ and carbamate pesticides. The objectives of this study were to determine the existing levels of whole-blood $\mathrm{ChE}$ of vegetable farmers, evaluate associations between activities of exposed farmers that encourage high exposures and wholeblood $\mathrm{ChE}$, and describe the prevalence of symptoms attributable to pesticide exposure.

\section{Materials and Methods}

A sampling frame for this study was constructed from data available on vegetable production from the Ministry of Food and Agriculture (MoFA), crop protection from Plant Protection and Regulatory Services Directorate at MoFA, as well as information obtained from Nurah (1999). From this information, and for other practical reasons, it was decided to conduct the study in the vegetable farming community of Akumadan $\left(1^{\circ} 57\left(\mathrm{~W}, 7^{\circ} 24(\mathrm{~N})\right.\right.$ in Offinso District of Ashanti Region, Ghana (Fig. 1). At Akumadan, the population of about 25,000 is engaged largely in vegetable farming. Among the major vegetables cultivated are pepper, garden eggs (eggplants), okra, and tomatoes. Of the vegetables cultivated, tomatoes alone constitute over $90 \%$. The tomato season runs throughout the whole year (Ntow 2001). At Akumadan, a wide and changing array of pesticides is utilized in the cultivation of vegetables. Table 1 lists the types and trade names of pesticides used and their application. According to the severity of infestation, either one or a combination of two or three of the organochlorine (OC), OP, carbamate, or pyrethroid insecticides was applied during the crop-growing season. The pesticides were applied mostly by knapsack sprayers (portable backpack sprayer, carrying capacity $15 \mathrm{~L}$ ) and rarely by hand (brush, broom, or leaves tied together to splash pesticides from a bucket). Sprayers were exposed by both inhalation and skin contact and, occasionally, ingestion of contaminated food and/or drinking water.

The target population was farmers, of either gender, 18 years or above, from Akumadan working in vegetable farms and applying pesticides during the spray season (exposed). The principal investigator initially contacted the farmers through their chiefs, group leaders, and/or fellow farmers to afford a forum to explain the purpose of the study. About 800 applicators of pesticides were initially recruited into the study. The control group consisted of farmers who had not handled pesticides in at least the preceding 2 months, who were initially selected from the Tono Irrigation Project at Tono near Navrongo in KassenaNankana Disrict of Upper East Region of Ghana (Fig. 1). About 2 months prior to the study, farmers at the Tono Irrigation Project were not farming (and for that matter spraying pesticides) because the water-pumping system was damaged. The ideal approach was to monitor changes in blood ChE activity of the study population during the agricultural season. Each farmer could then serve as his control. In practice, this was difficult to do because the farmers worked all through the year. According to Coye et al. (1986), a period of at least 30 days must separate the baseline determination from the farmer's last exposure to a ChE-inhibiting compound. This was difficult to achieve due to the farmers' commitment to their duties. The mean whole-blood ChE level obtained for the population at the Tono Irrigation Project, therefore, served as a reference. Rama and Jaga (1992) have used literature values as a reference for their study on farm workers in the Republic of South Africa.

The estimated number of farmers using pesticides at Akumadan was 96\% (A. Owusu, personal communication). The sample size was determined in order to have $95 \%$ confidence limits of 5\% maximum error of the estimate, when the prevalence is 96\% (Hogg and Tanis 1997; Wadsworth 1990). This leads to a requirement of about 60 farmers for Akumadan. For a no-response expectation, the sample size was increased to 100 farmers. Thus, a sample of 100 farmers who represented a random sample from the population of exposed farmers $(N=800)$ was selected for the study. Similarly, 100 farmers from the population of control farmers from the Tono Irrigation Project were selected for the study.

All participants gave informed consent after receiving oral and/or written information on the project. The Ethics Review Committee of the Health Research Unit of the Ghana Health Service approved the study.

At midday from about 12:00 PM to 3:30 PM in the field, during which the farmers had rest and/or avoided exposure to the high temperature at that part of the day, blood was drawn with heparin-treated syringes and needles with the assistance of health workers and transferred to 5-mL disposable plastic tubes already containing EDTA anticoagulant. Samples were placed in an ice-cooled chest and delivered to the nearest hospital within $1 \mathrm{~h}$ for storage at $-20^{\circ} \mathrm{C}$. Samples were later transported to the laboratory in Accra for analysis. 


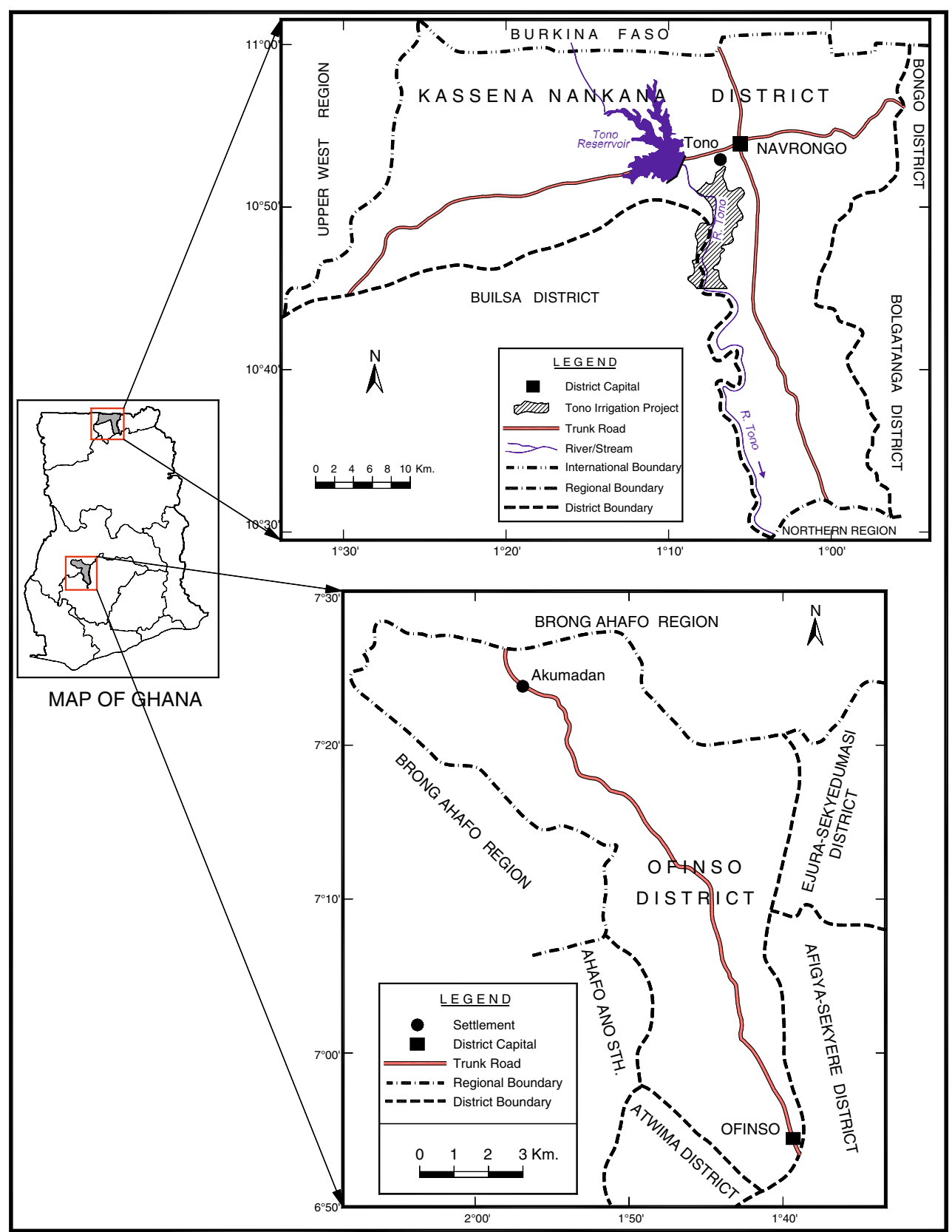

Fig. 1 Map of Ghana showing the study area, Akumadan, and the Tono Irrigation Project site in Kassena-Nankana district

A Gallenkamp UV-visible spectrophotometer was used throughout the study for the measurement of $\mathrm{ChE}$ activity. The instrument was calibrated for wavelength and absorbance in accordance with the manufacturer's instructions. All of the reagents used in the study were of analytical grade and used without any further purification. Acetylthiocholine iodide (ATC) and 5,5(-dithiobis-2nitrobenzoic acid) (DTNB) were purchased from SigmaAldrich Chemical Co. (Germany).

For the DTNB reagent $(10 \mathrm{mmol} / \mathrm{L}), 61 \mathrm{~mL}$ of $100 \mathrm{mmol} / \mathrm{L}(14.2 \mathrm{~g} / \mathrm{L}) \mathrm{Na}_{2} \mathrm{HPO}_{4}$ and $39 \mathrm{~mL}$ of $100 \mathrm{mmol} /$ $\mathrm{L} \mathrm{NaH}_{2} \mathrm{PO}_{4}(13.8 \mathrm{~g} / \mathrm{L})$ were mixed. The $\mathrm{pH}$ of the resulting solution was checked (if too low, dibasic salt was added to reach $\mathrm{pH}=7$, and if too high, monobasic salt was added to reach $\mathrm{pH}=7$ ). Then $39.6 \mathrm{mg}$ of DTNB was dissolved in $10 \mathrm{~mL}$ of the $100 \mathrm{mmol} / \mathrm{L}$ of sodium phosphate dibasic buffer. The reagent was stored in a dark bottle at $4^{\circ} \mathrm{C}$. For the ATC substrate $(75 \mathrm{mmol} / \mathrm{L}), 5 \mathrm{~mL}$ of $100 \mathrm{mmol} \mathrm{NaH}_{2} \mathrm{PO}_{4}$ $(13.8 \mathrm{~g} / \mathrm{L})$ and $95 \mathrm{~mL}$ of $100 \mathrm{mmol} \mathrm{Na} \mathrm{HPO}_{4}(14.2 \mathrm{~g} / \mathrm{L})$ were mixed. The $\mathrm{pH}$ of the resulting solution was checked (if too low, dibasic salt was added to reach $\mathrm{pH}=8$, and if too high, monobasic salt was added to reach $\mathrm{pH}=8$ ). Then $21.7 \mathrm{mg}$ of ATC was dissolved in $10 \mathrm{~mL}$ of the $100 \mathrm{mmol} / \mathrm{L}$ of sodium phosphate monobasic buffer. 
Table 1 Pesticides used for spraying vegetable crops at Akumadan, Ghana, February 2005 to January 2006 a Depending on the type of vegetable crop and also on farmer's knowledge

b Anti-cholinesterase agents

\begin{tabular}{|c|c|c|c|}
\hline $\begin{array}{l}\text { Types and trade names } \\
\text { of used pesticides }\end{array}$ & $\begin{array}{l}\text { Active ingredient } \\
\text { (a.i.) }\end{array}$ & $\begin{array}{l}\text { Application rate } \\
\text { (kg a.i./ha) }\end{array}$ & $\begin{array}{l}\text { No of } \\
\text { applications }\end{array}$ \\
\hline \multicolumn{4}{|c|}{ Organochlorine compounds } \\
\hline Thionex 35 EC/ULV & Endosulfan & $0.04-1.0$ & $6-12$ \\
\hline Thiodan $50 \mathrm{EC}$ & Endosulfan & $0.02-0.8$ & $6-12$ \\
\hline \multicolumn{4}{|c|}{ Organophosphorus compounds } \\
\hline Dursban $4 \mathrm{E}$ & Chlorpyrifos & $0.04-0.6$ & $6-12$ \\
\hline Perferkthion 400 EC & Dimethoate $^{\mathrm{b}}$ & $0.04-0.8$ & $6-12$ \\
\hline \multicolumn{4}{|l|}{ Carbamate compounds } \\
\hline Furadan $3 \mathrm{G}$ & Carbofuran ${ }^{*}$ & $0.06-0.9$ & $6-12$ \\
\hline Kontakt & Phenmedipham & $0.06-0.8$ & $6-12$ \\
\hline Dithane M-45 & Mancozeb & $0.04-0.9$ & $6-12$ \\
\hline Trimangol 80 & Maneb & $0.04-0.8$ & $6-12$ \\
\hline \multicolumn{4}{|l|}{ Pyrethroids } \\
\hline Karate $2.5 \mathrm{EC} / \mathrm{ULV}$ & Lambda cyhalothrin & $0.01-0.2$ & $6-12$ \\
\hline Cyperdin & Cypermethrin & $0.02-0.6$ & $6-12$ \\
\hline Cymbush & Cypermethrin & $0.02-0.6$ & $6-12$ \\
\hline Decis & Deltamethrin & $0.01-0.8$ & $6-12$ \\
\hline
\end{tabular}

For each farmer, whole-blood ChE activity was assayed in triplicate according to procedures of Ellman et al. (1961). The analytical reproducibility coefficient of variation, CV \% ranged from $1.28 \%$ to $1.94 \%$ in serially drawn samples. A half milliliter of blood sample was thawed and diluted to $10 \mathrm{~mL}$ with a freshly prepared $100 \mathrm{mmol} / \mathrm{L}$ sodium phosphate monobasic buffer $(\mathrm{pH}=8)$. Then $30 \mathrm{~mL}$ of $100 \mathrm{mmol} / \mathrm{L}$ sodium phosphate buffer $(\mathrm{pH}=8)$ and $1 \mathrm{~mL}$ of DTNB were added to $1 \mathrm{~mL}$ of the diluted blood. The solution was mixed thoroughly and incubated at $30^{\circ} \mathrm{C}$ for $10 \mathrm{~min}$. The spectrophotometric zero was set with this solution ( $3 \mathrm{~mL}$ pipetted into a curvette), after which $133 \mu \mathrm{L}$ of ATC solution was added. The rate of reaction was monitored in kinetic mode by a spectrophotometer at $412 \mathrm{~nm}$ for $6 \mathrm{~min}$ at $30^{\circ} \mathrm{C}$. The enzyme activity was expressed as micromoles of thiocholine hydrolyzed per minute per milliter of whole blood using an extinction coefficient of $13,600 / \mathrm{cm} / \mathrm{M}$.

A structured questionnaire in English was used to collect information from the farmers. The principal investigator translated the questionnaire into local and easily understandable languages, taking care to retain their original meaning. In some instances, the principal investigator sought assistance from other farmers to translate the questionnaire into the local language. The questionnaire consisted of both open and closed questions. We asked for four groups of data: (1) personal, (2) lifestyle (i.e., hygiene, eating, smoking and drinking habits), (3) farm details and work history, and (4) pesticide use practices and management. Additional questions were asked on pesticide-exposure symptoms during the preceding week. Some of the questions included in the questionnaire are not relevant to the present article. The questionnaires were administered at various locations, including farmers' homes, farms, and school classrooms.

SPSS software (SPSS software, version 12.0.1 for Windows; SPSS Inc, Chicago, IL, USA) was used for all statistical analyses. First, we summarized responses from the questionnaire over the exposed and control groups with regard to their demographic characteristics. The independent $t$-test was used for bivariate comparisons between means. Categorical variables were compared by the $\chi^{2}$ test. Multiple linear regression analysis was carried out to evaluate the contribution of demographic characteristics and exposure to $\mathrm{ChE}$ activities. For the comparison of symptoms according to exposure, we used the odds ratio for the prevalence as a measure of association. A level of probability below 0.05 was considered statistically significant for all analysis. Two-tailed $p$-values are given throughout. The results of the $\mathrm{ChE}$ activities were analyzed for normal distribution (Kolmogorov-Smirnov test) and homogeneity of variance (Levene's test).

\section{Results}

Subjects who refused to allow their blood samples to be taken were not evaluated, so the overall participation rate among the exposed and control groups were about $60 \%$. Therefore, the final study population consisted of 63 exposed subjects and 58 unexposed controls. The sample size is considered adequate for the desired level of confidence and precision.

The normal reference mean ChE activity adopted in this study is the one calculated from the control group. No 
Table 2 Demographic characteristics and $\mathrm{ChE}$ activity $(\mu \mathrm{mol} / \mathrm{min} / \mathrm{mL}$ of whole blood) of exposed and control participants
${ }^{a}$ Independent $t$-test

b $\chi^{2}$ test

${ }^{c}$ Deviation from $N$ is due to missing answer to the specific question

${ }^{\mathrm{d}}$ Normal reference mean: $7.27 \mu \mathrm{mol} / \mathrm{min} / \mathrm{mL}$ of whole blood

\begin{tabular}{|c|c|c|c|c|}
\hline \multirow[t]{2}{*}{ Characteristic } & \multicolumn{2}{|l|}{ Community } & \multirow[t]{2}{*}{ Test of significance } & \multirow[t]{2}{*}{$p$-Value } \\
\hline & $\begin{array}{l}\text { Exposed } \\
\text { participants } \\
(N=63)\end{array}$ & $\begin{array}{l}\text { Control } \\
\text { participants } \\
(N=58)\end{array}$ & & \\
\hline \multicolumn{5}{|l|}{ Age (years) } \\
\hline Mean (SD) & $33.9(8.51)$ & $32.3(9.80)$ & $-0.418^{\mathrm{a}}$ & 0.678 \\
\hline \multicolumn{5}{|l|}{ Gender, $N(\%)$} \\
\hline Male & $33(52)$ & $38(66)$ & & \\
\hline Female & $30(48)$ & $20(34)$ & $2.15^{\mathrm{b}}$ & 0.143 \\
\hline \multicolumn{5}{|l|}{ Duration of work as farmer (years) } \\
\hline Mean (SD) & $17.1(5.30)$ & $14.2(6.10)$ & $1.36^{\mathrm{a}}$ & 0.177 \\
\hline \multicolumn{5}{|l|}{ Height (m) } \\
\hline Mean (SD) & $1.61(0.130)$ & $1.64(0.093)$ & $-1.23^{\mathrm{a}}$ & 0.220 \\
\hline \multicolumn{5}{|l|}{ Weight (kg) } \\
\hline Mean (SD) & $63.8(9.90)$ & $61.2(10.2)$ & $1.43^{\mathrm{a}}$ & 0.156 \\
\hline \multicolumn{5}{|l|}{ Smoking, $N^{\mathrm{c}}(\%)$} \\
\hline Yes & $7(11.1)$ & $3(5.17)$ & & \\
\hline No & $56(88.9)$ & $43(74.1)$ & $0.672^{\mathrm{b}}$ & 0.514 \\
\hline \multicolumn{5}{|l|}{ Drinking, $N^{*}(\%)$} \\
\hline Yes & 13 (20.6) & $33(56.9)$ & & \\
\hline No & $49(77.8)$ & $13(22.4)$ & $27.84^{\mathrm{b}}$ & $<0.001$ \\
\hline Mean ChE (SD) & $3.59(2.93)$ & $7.27(1.71)$ & $-8.506^{\mathrm{a}}$ & $<0.001$ \\
\hline $\begin{array}{l}\% \text { Falling below a level at } 70 \% \text { of } \\
\text { normal reference mean }^{\mathrm{d}}\end{array}$ & 73.0 & 13.8 & & \\
\hline
\end{tabular}

study had been done in Ghana to establish a reference whole-blood ChE activity. However, a study conducted in South Africa that established a reference range for serum ChE indicates a reference range fairly similar to that adopted in this study (Rama and Jaga 1992). Ideally, it is best to compare the farmer's postexposure ChE level with their own baseline value. This was not possible in this study. Thus, the levels of ChE determined here for the controls served as baseline values for comparisons of the health effects of pesticide exposure.

Table 2 depicts the demographic characteristics of the farmers at Akumadan and the controls at Tono. The mean age of the exposed participants (33.9 years) was slightly older than that of controls (32.3 years), but the difference was not significant ( $p=0.678$ ) (see Table 2 ). The mean duration of work as a farmer of the exposed participants was 17.1 years, and the mean of the control group was 14.2 years. This difference was also not significant $(p=0.177)$. Exposed participants, on the average, weighed heavier than the control participants, although the difference was not statistically significant ( $p=0.156$ ). On the other hand, the control participants were taller than the exposed participants and, again, the difference was not statistically significant ( $p=0.220)$. Measures reflecting lifestyle choices did not differ between the two groups except for drinking. Self-report of smoking habits of the two groups was not significantly different $(\mathrm{p}=0.514)$. However, drinking habits differed significantly $(p<0.001)$ for the exposed and control groups.

The mean whole-blood ChE activity of farmers at Akumadan $(3.59 \mu \mathrm{mol} / \mathrm{min} / \mathrm{ml}$ blood $)$ was $50.6 \%$ less than that of farmers considered unexposed from the Tono Irrigation Project $(7.27 \mu \mathrm{mol} / \mathrm{min} / \mathrm{ml}$ blood $)$ and the difference was highly significant $(p<0.001)$. Levels of ChE were thus significantly lower in exposed farmers than in controls. The percentage of exposed vegetable farmers with a reduction of $30 \%$ in whole-blood ChE activity was about $73 \%$ (Table 2). Although the groups did not differ significantly with respect to age, sex, height, and body weight, these variables are so well established as confounders of ChE activity in humans (Nielsen and Andersen 2002) that multiple linear regression analysis was used to adjust for their influence. After adjustment for confounders, whole-blood $\mathrm{ChE}$ was not influenced significantly for either exposed $(F=0.043$, df $=4,56, p=0.996)$ or the control group $(F=0.128, \mathrm{df}=4,52, p=0.972)$. None of the four confounders has significant influence on wholeblood ChE (Table 3). Furthermore, work practices that encourage high exposures and, therefore, hypothesized to be associated with changes in ChE activity had no significant effect $(F=0.328$, df $=4,57, p=0.858)$ on $\mathrm{ChE}$ activity of exposed participants. Clearly, none of the four practices (method of pesticide application, direction of 
Table 3 Multiple linear regression model for predicting the relationship between ChE activity and demographic characteristics of exposed and control participants

\begin{tabular}{|c|c|c|c|c|c|c|}
\hline \multirow[t]{2}{*}{ Variable (unit) } & \multicolumn{3}{|c|}{ Exposed $(N=63)$} & \multicolumn{3}{|l|}{ Control $(N=58)$} \\
\hline & $\beta(\mathrm{SE})$ & Test of significance & $p$-Value & $\beta(\mathrm{SE})$ & Test of significance & $p$-Value \\
\hline Age (years) & $-0.015(0.046)$ & -0.318 & 0.751 & $0.003(0.019)$ & 0.158 & 0.875 \\
\hline Sex $($ female $=0$, male $=1)$ & $0.181(1.19)$ & 0.152 & 0.880 & $0.419(0.741)$ & 0.566 & 0.574 \\
\hline Weight (kg) & $-0.006(0.042)$ & -0.132 & 0.895 & $-0.001(0.024)$ & -0.047 & 0.962 \\
\hline Height (m) & $0.264(3.11)$ & 0.085 & 0.932 & $-0.994(2.56)$ & -0.389 & 0.699 \\
\hline Constant & $4.04(5.70)$ & 0.708 & 0.482 & $8.42(4.26)$ & 1.98 & 0.053 \\
\hline$R^{2}$ & 0.003 & & & 0.010 & & \\
\hline
\end{tabular}

spraying of pesticide, kind of protective cover, and farmer reentry period) was significantly associated with changed concentrations of ChE activity (Table 4).

Farmers recalled symptoms, attributable to pesticide exposure, they had experienced within the week preceding the interview. Self-reported symptoms of body weakness, headache, and stomach pain were higher in the exposed group than in the control group. The difference was significant $(p<0.05)$ for body weakness alone. Although self-reported symptoms of vomiting and body itching were lower in the exposed participants, they were not significant (Table 5). Exposed participants reported significantly $(p<0.05)$ more symptoms attributable to pesticide exposure than the controls.

\section{Discussion}

Our study demonstrated a statistically significant $(p<0.001)$ pattern of lower blood ChE activity in farmers at Akumadan compared to controls. The WHO biological index for individuals occupationally exposed to pesticides has been set to $30 \%$ of ChE depression (WHO Study Group 1982). Accordingly, in the present study, a ChE depression at or above $30 \%$ was selected to quantitatively estimate exposure to pesticides. Thus, any factor associated with a ChE depression greater than $30 \%$ could be attributed to pesticide exposure. In spite of this, $\sim 73 \%$ of all exposed farmers had blood $\mathrm{ChE}$ activity levels at or below $70 \%$ of the normal reference mean. Acute overexposure and chronic moderate exposure to pesticides can result in an inhibition of ChE. However, symptoms depend more on the rate of fall in $\mathrm{ChE}$ activity than on the absolute level reached (Barnes 1999).

The observation of lowered blood ChE activity in farmers at Akumadan is probably due to unsafe working habits promoted by self-desires to have rapid knockdown of pests and increase income. Akumadan lies in the agricultural zone of the Ashanti Region of Ghana. The community at Akumadan is noted for the cultivation of

Table 4 Multiple linear regression model for predicting the relationship between ChE activity and work practices that encourage high exposures and poisoning potentials among exposed farmers $(N=63)$

\begin{tabular}{llll}
\hline & $\beta(\mathrm{SE})$ & Test of significance & $p$-Value \\
\hline Method of pesticide application & $0.271(0.724)$ & 0.375 & 0.709 \\
Direction of spraying of pesticide & $0.197(0.292)$ & 0.675 & 0.503 \\
Kind of protective cover & $0.748(1.06)$ & 0.703 & 0.485 \\
Farmer reentry periods & $0.269(0.559)$ & 0.481 & 0.632 \\
\hline
\end{tabular}

Table 5 Prevalence (\%) and odds ratio of self-reported symptoms attributable to pesticide exposure in exposed and control participants

\begin{tabular}{lcccr}
\hline Self-reported symptoms & $\begin{array}{l}\text { Exposed }(N=62) \\
N(\%)\end{array}$ & $\begin{array}{l}\text { Control }(N=58) \\
N(\%)\end{array}$ & OR & 95\% CI \\
\hline Vomiting & $2(3.2)$ & $5(8.6)$ & 0.348 & $0.065-1.87$ \\
Weakness & $31(50.0)$ & $12(20.7)$ & 3.71 & $1.66-8.30$ \\
Headache & $20(32.3)$ & $19(32.8)$ & 0.955 & $0.445-2.05$ \\
Itching & $2(3.2)$ & $3(5.2)$ & 0.601 & $0.097-3.73$ \\
Stomach pain & $5(8.1)$ & $4(6.9)$ & 1.16 & $0.297-4.56$ \\
No symptoms & $2(3.2)$ & $15(25.9)$ & 0.094 & $0.020-0.432$ \\
\hline
\end{tabular}

OR, odds ratio; $\mathrm{CI}$, confidence interval 
various vegetables (pepper, eggplants, onions, tomatoes, okra, etc.) and pesticide applications frequently occur. Both anecdotal evidence and available data of farmers' use of pesticides at Akumadan indicate that they do not typically utilize recommended doses nor do they utilize the chemical industry's recommended practices for safe storage, handling, and application. There appear to be many reasons for this state of affairs (Ntow et al. 2006). On the one hand, most farmers at Akumadan have little (64.9\% comprising primary and middle) or no formal education (12.7\%) (Ntow et al. 2006). Although their traditional farming knowledge is adequate for them to benefit from the trade, effective and safe chemical pest management requires knowledge that goes beyond traditional farming practices (Antle and Pingali 1995). A wide and changing array of insecticides, herbicides, and other pesticides are available to farmers, but little extension is available to guide farmers in their use, and most have not received training for safe storage, handling, and application. Most farmers rely on the recommendations of chemical dealers or their own experience in deciding how to use pesticides. The majority (66.7\%) of the farmers represented in this study used knapsack sprayers to apply toxic pesticides, but none took effective self-protection measures when working in the field with these materials.

The pattern of lowered blood ChE activity in exposed participants compared to controls was supported by multiple regression analysis, which adjusted for age, sex, body weight, and height - strong contributors to ChE activity in humans (Nielsen and Andersen 2002). The decreases in ChE activity were seen in self-reported symptoms attributable to pesticide exposure, particularly body weakness and headache (Table 5). About $97 \%$ of the population of vegetable farmers at Akumadan (exposed group) have reported symptoms attributable to pesticide exposure in the week preceding the survey. The symptom significantly $(p<0.05)$ reported by farmers is body weakness. This symptom is considered a common manifestation of cholinesterase inhibition (Quinones et al. 1976; Yassin et al. 2002).

In the questionnaire, we had a strong focus on work practices and the use of personal protective equipment. Work practices involving use of personal protective clothing, method of application of pesticide, farmer reentry intervals, and direction of spraying of pesticides were not associated with changed concentrations of ChE activity, although all four practices are hypothesized to be associated with changes in ChE activity. These practices are not governed by strict regulations concerning the training and education of farmers. As information from the questionnaire and previous work (Clarke et al. 1997; Ntow et al. 2006) revealed that farmers' handling and storage of chemical pesticides, personal hygiene, and the proper use of personal protective equipment in Ghana is below a reasonable standard, it is unexpected that the biological exposure marker failed to demonstrate an equivalent result.

The interpretation of the relations in this study, however, is not unequivocal and is complicated by some methodological inadequacies in the study. A small sample size limits the significance of this study. However, it paves the way for a larger Ghanaian study with extended practical significance.

Other study limitations included the possible influence of bias. Most of the data were self-reported, which could introduce a strong information (responder) bias because respondents might have presented inaccurate information either in the hope of secondary gain or to avoid adverse outcomes, such as being investigated by authorities. Additionally, the lack of income for the control farmers who had not been farming for 2 months might have caused stress and related problems, possibly causing bias in the survey.

The criterion used for classifying study participants into exposed and a control group makes it difficult to reach significant differences, as they were all farmers with either direct or indirect exposure to pesticides. It would have been of most interest to monitor changes in blood ChE activity of the study population during the agricultural season, in which each farmer could then serve as his control. This might weaken our study by making associations more difficult to detect, although it does not undermine the validity of any observed associations.

\section{Conclusions}

Based on the findings of the present study, we conclude that in agricultural areas where pesticides are applied indiscriminately and for extended periods of the year, farmers might be exposed to high levels of ChE-inhibiting pesticides. This exposure might result in depressed $\mathrm{ChE}$ activity. We will confirm this finding by a methodology in which both peak and nonpeak exposure periods of the farmers will be sampled and which could also address interindividual and intraindividual variation of ChE activity. The small sample size and lack of preexposure baseline measurements of $\mathrm{ChE}$ for the exposed group preclude more definite conclusions.

\section{Policy Implications}

Our findings stress the need to review safety precautions in the use and application of pesticides in Ghana. The abuse, misuse, and the use of a wide range of pesticides, mostly of moderate to high toxicity in the country, implies high exposures and possible poisoning potentials and would 
suggest the need for more control and monitoring at national and local levels. An immediate priority in Ghana is an urgent requirement for sustained, low-cost, and welltargeted training interventions.

Acknowledgments The authors thank Augustina Kumapley, Rafia Mamudu, and vegetable farmers in Ghana for their assistance and cooperation. This study was funded by the Dutch Government (through the UNESCO-IHE Institute for Water Education, Delft), International Water Management Institute, and the International Foundation for Science.

Open Access This article is distributed under the terms of the Creative Commons Attribution Noncommercial License which permits any noncommercial use, distribution, and reproduction in any medium, provided the original author(s) and source are credited.

\section{References}

Antle JM, Pingali PL (1995) Pesticides, productivity, and farmer health: a Philippine case study. In: Pingali PL, Roger PA (eds) Impact of pesticides on farmer health and the rice environment. Kluwer Academic, Boston, MA, pp 361-387

Barnes JM (1999) Problems in monitoring overexposure among spray workers in fruit orchards chronically exposed to diluted organophosphate pesticides. Int Arch Occup Environ Health 72(Suppl 3): M68-M74

Clarke E, Levy LS, Spurgeon A, Calvert LA (1997) The problems associated with pesticide use by irrigation workers in Ghana. Occup Med 47:301-308

Coye M, Barnett PG, Midttling JE (1986) Clinical confirmation of organophosphate poisoning of agricultural workers. Am J Ind Med 10:399-409

Ellman GL, Courtney KD, Andres Jr V, Featherstone RM (1961) A new and rapid colorimetric determination of acetylcholinesterase activity. Biochem Pharmacol 7:88-95

Farahat TM, Abdelrasoul GM, Amr MM, Shebl MM, Farahat FM, Anger WK (2003) Neurobehavioural effects among workers occupationally exposed to organophosphorus pesticides. Occup Environ Med 60:279-286, doi:10.1136/oem.60.4.279 (Online 14 November 2005)
Fenske RA, Lu C, Curl CL, Shirai JH, Kissel JC (2005) Biologic monitoring to characterise organophosphorus pesticide exposure among children and workers: an analysis of recent studies in Washington State. Environ Health Perspect 113(11):1651-1657

He F (1993) Biological monitoring of occupational pesticides exposure. Int Arch Occup Environ Health 65:S69-S76

Hogg RV, Tanis EA (1997) Probability and statistical inference, 5th ed. Prentice Hall, Englewood Cliffs, NJ

Nielsen JB, Andersen HR (2002) Cholinesterase activity in female greenhouse workers: influence of work practices and use of oral contraceptives. J Occup Health 44:234-239

Ntow WJ (2001) Organochlorine pesticides in water, sediment, crops and human fluids in a farming community in Ghana. Arch Environ Contam Toxicol 40(4):557-563

Ntow WJ, Gijzen HJ, Kelderman P, Drechsel P (2006) Farmer perceptions and pesticide use practices in vegetable production in Ghana. Pest Manag Sci 62:356-365

Nurah GK (1999) A baseline study of vegetable production in Ghana. National Agricultural Research Project (NARP) Report. CSIR Water Research Institute, Accra, Ghana

Ohayo-Mitoko GJA, Kromhout H, Simwa JM, Boleij JSM, Heederik D (2000) Self reported symptoms and inhibition of acetylcholinesterase activity among Kenyan agricultural workers. Occup Environ Med 57:195-200, doi:10.1136/oem.57.3.195 (Online 14 November 2005)

Quinones MA, Bogden JD, Louria DB, Nakah AE (1976) Depressed cholinesterase activities among farm workers in New Jersey. Sci Total Environ 6:155-159

Rama DBK, Jaga K (1992) Pesticide exposure and cholinesterase levels among farm workers in the Republic of South Africa. Sci Total Environ 122:315-319

Wadsworth HM Jr (1990) Handbook of statistical methods for engineers and scientists. McGraw-Hill, New York

WHO Study Group (1982) Recommended health-based limits in occupational exposure to pesticides. Technical Report Series 677. World Health Organization, Geneva

WHO Task Group (1986a) Organophosphorus insecticides: A general introduction. Environmental Health Criteria 63. World Health Organization, Geneva

WHO Task Group (1986b) Carbamate pesticides: A general introduction. Environmental Health Criteria 64. World Health Organization, Geneva

Yassin MM, Abu Mourad TA, Safi JM (2002) Knowledge, attitude, practice, and toxicity symptoms associated with pesticide use among farm workers in the Gaza Strip. Occup Environ Med 59:387-393 